\title{
Effects of humic acid on copper adsorption onto few-layer reduced graphene oxide and few-layer graphene oxide
}

\author{
Shuang Yang ${ }^{a}$, Lingyun $\mathrm{Li}^{b}$, Zhiguo Pei ${ }^{a, *}$, Chunmei $\mathrm{Li}^{a}$, Xiao-quan Shan ${ }^{a}$, Bei Wen ${ }^{a}$, \\ Shuzhen Zhang ${ }^{a}$, Lirong Zheng ${ }^{c}$, Jing Zhang ${ }^{c}$, Yaning Xie ${ }^{c}$, Rixiang Huang ${ }^{d}$ \\ a State Key Laboratory of Environmental Chemistry and Ecotoxicology, Research Center for Eco-Environmental Sciences, Chinese Academy of \\ Sciences, PO Box 2871, Beijing 100085, China \\ ${ }^{\mathrm{b}}$ Supervision and Testing Center for Vegetable Quality, Ministry of Agriculture, The Institute of Vegetables and Flowers, Chinese Academy of \\ Agricultural Sciences, Beijing 100081, China \\ c Beijing Synchrotron Radiation Laboratory, Institute of High Energy Physics, Chinese Academy of Sciences, Beijing 100049, China \\ d Department of Geology, Baylor University, One Bear Place \#97354, Waco, TX 76798, USA
}

\section{A R T I C L E I N F O}

Article history:

Received 16 October 2013

Accepted 29 March 2014

Available online 5 April 2014

\begin{abstract}
A B S T R A C T
The effects of humic acid (HA) on copper $(\mathrm{Cu}(\mathrm{II}))$ adsorption onto few-layer reduced graphene oxide (FRGO) and few-layer graphene oxide (FGO) were investigated using a batch equilibration method, micro-Fourier transform infrared spectroscopy, and extended X-ray absorption fine structure spectroscopy (EXAFS). The results showed that HA was adsorbed on FRGO through $\pi-\pi$ interaction. The adsorbed HA introduced O-containing functional groups and negative charges to FRGO surfaces, increasing $\mathrm{Cu}(\mathrm{II})$ adsorption through chemical complexation and electrostatic attraction. In contrast, HA was adsorbed onto FGO mainly through polar interactions, due to its rich O-containing functional groups. The adsorbed HA had little effect on $\mathrm{Cu}$ (II) adsorption onto FGO because the shielding effect of $\mathrm{HA}$ on $\mathrm{Cu}(\mathrm{II})$ adsorption was offset by newly introduced adsorption sites of HA on FGO. EXAFS results suggested that $\mathrm{Cu}(\mathrm{II})$ was adsorbed on FRGO and FGO mainly through the coordination with their O-containing functional groups. When HA was added at $\mathrm{pH} 4.0$ and 6.0, more $\mathrm{Cu}$ (II) was adsorbed on HA-coated FRGO. At pH 8.0, a portion of $\mathrm{Cu}$ (II) in solution precipitated on FRGO surface, while the presence of HA led to the formation of FRGO-HA-Cu ternary surface complexes instead of $\mathrm{Cu}$ (II) precipitation.
\end{abstract}

(c) 2014 Elsevier Ltd. All rights reserved.

\section{Introduction}

Graphene-based nanomaterials (GBNs) are ideal twodimensional materials with thickness of only one atomic layer, and have recently attracted considerable attention due to their distinct and unique physicochemical properties [1]. GBNs are considered promising candidates in many areas of nanotechnological applications, including their use as sorbents for the removal of recalcitrant contaminants from water [2-8]. However, rapid increase in the production and

\footnotetext{
* Corresponding author: Fax: +861062923563.

E-mail address: peizg@rcees.ac.cn (Z. Pei). 
application of GBNs has triggered serious concerns about their potential adverse effects on both the environment and human health due to their inevitable release into the environment [9].

Humic acid (HA) is ubiquitous in natural waters and has been found to interact with nanomaterials in the environment [10]. The interactions between HA and nanomaterials not only alter the surface properties and environmental behavior of these nanomaterials, but also affect the adsorption of coexisting contaminants $[10,11]$. Hyung et al. [12] revealed that dissolved organic matter (DOM) could bind with carbon nanotubes in aquatic systems through $\pi-\pi$ interaction, and the steric and electrostatic stabilization offered by DOM greatly enhanced their stability and transport in water [13]. Shi et al. [14] reported that the presence of HA helped inhibit the formation of fullerene aggregates and increased its dispersion in solution, consequently atrazine adsorption on fullerenes was enhanced. Additionally, HA could also coat on the surface of titanium dioxide and ferroferric oxide nanoparticles, making removal of heavy metals from water more effective $[15,16]$. As for GBNs, little information is available regarding the interactions between GBNs and HA, and their subsequent effects on the adsorption of coexisting contaminants. Previous studies usually examined the adsorption of contaminants by GBNs in single solute system [17-22]. Results showed that graphene oxide was an effective adsorbent for the removal of heavy metal from water due to the coordination between metal ion and O-containing functional groups of graphene oxide [17-19]. In addition, the adsorption of lead on graphene was attributed to the occurrence of electrostatic and Lewis acid-base interactions [23].

Though knowledge regarding HA interactions with carbon nanotubes is noteworthy and can help interpret the interactions between HA and GBNs, differences between carbon nanotubes and GBNs need to be considered. Compared to carbon nanotubes, GBNs are open layered structure and contain carbons of different saturation degrees and oxidation states. As a result, the differences in properties among GBNs are pronounced. Therefore, it is necessary to study the interactions between HA and GBNs with different structures and properties, and to examine their effects on the adsorption of coexisting contaminants.

In this work, we chose few-layer reduced graphene oxide (FRGO) and few-layer graphene oxide (FGO) with different $\pi$ electron density and O-containing functional groups as adsorbents to examine the interactions of HA with FRGO and FGO and their effects on $\mathrm{Cu}$ (II) adsorption. $\mathrm{Cu}$ (II) is an essential element for life at low concentration, but is toxic at high concentrations. It can be detected in most natural settings and accumulate in soils to a high level through the land application of fertilizers, sewage sludge, or wastewater irrigation [18]. The objectives of this study were (i) to examine the adsorption of HA on FRGO and FGO, (ii) to investigate the adsorption of $\mathrm{Cu}$ (II) on FRGO and FGO in the absence and presence of $\mathrm{HA}$, and (iii) to provide an insight into the mechanisms of $\mathrm{Cu}$ (II) adsorption on FRGO and FGO using extended X-ray absorption fine structure spectroscopy (EXAFS).

\section{Experimental}

\subsection{Materials}

FGO was prepared by a modified Hummers method [24], and FRGO was obtained by thermal exfoliation/reduction using graphite oxide as a precursor [25]. Detailed process has been provided in the "Supplementary data". $\mathrm{Cu}\left(\mathrm{NO}_{3}\right)_{2}$, $\mathrm{NaNO}_{3}, \mathrm{NaOH}$ and $\mathrm{HNO}_{3}$ are of analytical grade and were used as received. HA was isolated from a commercial peat (Klasmann-Deilmann $\mathrm{GmbH}$, Germany) according to the procedure of the International Humic Substances Society [26]. The obtained HA was dried, pulverized gently in a mortar to pass through a $0.25-\mathrm{mm}$ sieve, and stored in a glass vial at room temperature before use. The elemental compositions of HA are shown in Table S1. Solid-state ${ }^{13} \mathrm{C}$ nuclear magnetic resonance (NMR) spectrum was acquired using cross-polarization and magic angle spinning on a $300-\mathrm{MHz}$ NMR spectrometer (Varian, San Francisco). Spectra were acquired at a frequency of $75 \mathrm{MHz}$ for ${ }^{13} \mathrm{C}$ magic angle spinning rate of $13 \mathrm{kHz}$, contact time of $2 \mathrm{~ms}, 4 \mathrm{~s}$ recycle delay. The number of scans was from 5000 to 10,000 per sample. The results showed that percentages of aliphatic and aromatic carbon are $50.2 \%$ and $36.6 \%$, respectively (Fig. S1 and Table S2).

\subsection{Characterization of FRGO and FGO}

The surface functional groups of FRGO and FGO were determined by X-ray photoelectron spectroscopy (XPS) (PerkinElmer PHI 550 ESCA/SAM, U.S.) and Boehm titration [27,28]. Scanning electron microscope (SEM) images were obtained on a field emission scanning electron microscope (SU-8020). Transmission electron microscope (TEM) images were collected with a H-7500 (Hitachi, Japan). The size and thickness of FRGO and FGO were measured by means of atomic force microscopy (AFM) (Veeco Instrument Inc., Plainview, N.Y). Nitrogen specific surface areas of FRGO and FGO were estimated using an accelerated surface area system and Brunauer-Emmett-Teller (BET) equation to adsorption of $\mathrm{N}_{2}$ at $77 \mathrm{~K}$.

\subsection{Adsorption of HA on FRGO and FGO}

HA solution $\left(60.0 \mathrm{mg} \mathrm{L}^{-1}\right.$ ) was prepared in $0.01 \mathrm{M} \mathrm{NaNO}_{3}$ solution, to which $0.1 \mathrm{~g} \mathrm{~L}^{-1} \mathrm{NaN}_{3}$ was added to suppress the potential growth of bacteria. The obtained HA solutions were filtered through $0.22 \mu \mathrm{m}$ membrane filter before use. Adsorption of HA on FRGO and FGO as a function of solution $\mathrm{pH}$ were performed by mixing a certain amount of FRGO or FGO with $20.0 \mathrm{~mL} 0.01 \mathrm{M} \mathrm{NaNO}$ solution containing $30.0 \mathrm{mg} \mathrm{L}^{-1} \mathrm{HA}$ in $50.0 \mathrm{~mL}$ polyethylene centrifuge tubes. The $\mathrm{pH}$ was adjusted from 4.0 to 10.0 by the addition of $0.1 \mathrm{M} \mathrm{HNO}_{3}$ or $\mathrm{NaOH}$. The suspension was rotated continuously for $24 \mathrm{~h}$ at $23.0 \pm 1^{\circ} \mathrm{C}$ (apparent equilibrium was reached before this time, Fig. S2a). After centrifugation at $10,000 \mathrm{rpm}$ for $20 \mathrm{~min}$ and filtration with a $0.22 \mu \mathrm{m}$ membrane filter, HA concentrations in the filtrate were determined by an ultraviolet and visible spectrophotometer (U- 
3010, Hitachi, Japan) at $256 \mathrm{~nm}$ and calibrated with a total organic carbon analyzer (Shimadzu, Japan). Preliminary results showed no significant loss of $\mathrm{HA}$ after centrifugation and filtration.

\subsection{Adsorption of $\mathrm{Cu}(\mathrm{II})$ on FRGO and FGO as affected by HA}

All adsorption experiments were conducted in triplicate using a batch equilibration method at $23.0 \pm 1^{\circ} \mathrm{C}$. Prior to the initiation of $\mathrm{Cu}$ (II) adsorption, a certain amount of FRGO or FGO was transferred to $50.0 \mathrm{~mL}$ polyethylene centrifuge tubes, mixed with $10.0 \mathrm{~mL}$ different concentrations of HA solution, and rotated continuously for $24 \mathrm{~h}$. Afterwards, different volumes of $\mathrm{Cu}$ (II) stock solution were added to the tubes. The final volume of the equilibrium solution was adjusted to $20.0 \mathrm{~mL}$ with $0.01 \mathrm{M} \mathrm{NaNO}_{3}$ solution. The initial concentrations of $\mathrm{Cu}$ (II) were $0.1-2.5 \mathrm{mM}$, and the initial concentrations of HA were $0,15.0$ and $30.0 \mathrm{mg} \mathrm{L}^{-1}$. The suspension $\mathrm{pH}$ was adjusted to $5.0 \pm 0.1$ by addition of $0.1 \mathrm{M} \mathrm{HNO}_{3}$ or $0.1 \mathrm{M} \mathrm{NaOH}$. The suspension was rotated continuously for $24 \mathrm{~h}$ to ensure complete adsorption (apparent equilibrium was reached before this time, Fig. S2b). After centrifugation and filtration, the concentrations of $\mathrm{Cu}$ (II) in the filtrate were determined by inductively coupled plasma atomic emission spectrometry (ICP-AES) (IRIS Advantage, Thermo Elemental). The adsorbed $\mathrm{Cu}(\mathrm{II})$ was calculated from the differences between the initial and final equilibrium concentrations. Mass balance calculations were conducted by determining $\mathrm{Cu}$ (II) left in the equilibrium solution after $\mathrm{Cu}$ (II) adsorption onto FRGO or FGO, and the adsorbed $\mathrm{Cu}(\mathrm{II})$ on FRGO or FGO, which was extracted with $5.0 \% \mathrm{HNO}_{3}$ solution $(30 \mathrm{~mL}$ ) for three times. The total recovery was calculated from the sum of $\mathrm{Cu}$ (II) in the solution phase and the adsorbed $\mathrm{Cu}$ (II) on FRGO or FGO divided by the initial amount of $\mathrm{Cu}$ (II) added. The average recoveries of $\mathrm{Cu}$ (II) were $\geqslant 97.0 \%$ for both FRGO and FGO, indicating that the loss of $\mathrm{Cu}$ (II) in the adsorption process was negligible.

The pH effect on $\mathrm{Cu}$ (II) adsorption on FRGO or FGO in the absence and presence (15.0 and $30.0 \mathrm{mg} \mathrm{L}^{-1}$ ) of HA was conducted using a batch adsorption approach as mentioned above. The initial concentration of $\mathrm{Cu}$ (II) was $0.2 \mathrm{mM}$. After equilibrium was reached, suspension was centrifuged and filtered, and $\mathrm{Cu}$ (II) concentrations in the filtrate were determined by ICP-AES.

\subsection{Electrophoretic mobilities (EPMs) measurement}

The suspension for EPMs measurement was prepared by mixing a certain amount of FRGO or FGO with $20.0 \mathrm{~mL}$ $0.01 \mathrm{M} \mathrm{NaNO}$ solution including different concentrations of $\mathrm{HA}\left(0,15.0\right.$ and $\left.30.0 \mathrm{mg} \mathrm{L}^{-1}\right)$. The solution $\mathrm{pH}$ was adjusted using $0.1 \mathrm{M} \mathrm{HNO}_{3}$ or $\mathrm{NaOH}$. The suspension was rotated continuously for $24 \mathrm{~h}$ at room temperature $\left(23.0 \pm 1^{\circ} \mathrm{C}\right)$. The EPMs were determined on a ZetaSizer Nano ZS (Malvern Instruments, Worcestershire, U.K.). Five independent EPMs measurements were collected for each sample to ensure accurate and reproducible data.

\subsection{Micro-Fourier transform infrared ( $\mu$-FTIR) spectroscopy}

$\mu$-FTIR spectra were recorded on NICOLET in 10 MX (Thermo Scientific). Samples for $\mu$-FTIR analysis were prepared by mixing a certain amount of FRGO or FGO with $20.0 \mathrm{~mL}$ HA solution in polyethylene centrifuge tubes. After equilibrium, the suspensions were centrifuged, and the supernatant was discarded. HA-adsorbed FRGO or FGO were washed with $0.01 \mathrm{M}$ $\mathrm{NaNO}_{3}$ solution, and then freeze-dried overnight. Microsamples were pressed on a diamond bracket and $\mu$-FTIR spectra were measured. The resolution for $\mu$-FTIR spectra was $4 \mathrm{~cm}^{-1}$, and a total of 100 scans were collected for each spectrum. Difference spectra of HA-adsorbed samples were obtained by subtracting the spectrum of sole FRGO or FGO from the corresponding spectrum of HA-adsorbed FRGO or FGO.

\subsection{X-ray absorption spectroscopy}

The adsorbed samples were prepared according to above adsorption procedures, where the initial concentrations of $\mathrm{Cu}$ (II) and HA were $0.2 \mathrm{mM}$ and $30.0 \mathrm{mg} \mathrm{L}^{-1}$, respectively. Three $\mathrm{pH}$ values $(4.0,6.0$ and 8.0) were selected in the experiments. After centrifugation, the supernatant was discarded. $\mathrm{Cu}$ K-edge $(8979 \mathrm{eV}) \mathrm{X}$-ray absorption spectra of these wet pastes were collected at 1W1B beamline of the Beijing Synchrotron Radiation Facility using a Si (111) double-crystal monochromator. Data for all adsorption samples were collected in fluorescence mode under ambient conditions. An average of three scans was performed to achieve an adequate signal to noise ratio. The data were Fourier transformed over $k$-region of $3.3-12.0 \AA^{-1}$. Fitting was performed in $k$-space yielding optimal values for coordination numbers $(N)$ and atomic distances $(R)$, energy offset $\left(E_{0}\right)$, and Debye-Waller factors $\left(\sigma^{2}\right)$. Phase shifts and backscattering amplitudes were obtained from theoretical calculations using FEFF 8.0 [29]. Data analysis was performed using program WinXAS 3.1.

\subsection{Isotherm models}

Adsorption data were fitted to Freundlich and Langmuir equations using software Origin 7.5. Freundlich and Langmuir equations can be expressed as $Q=K_{\mathrm{f}} C^{n}$ and $\mathrm{Q}=\mathrm{K}_{\mathrm{L}} \mathrm{Qmax}_{\max } \mathrm{C} /$ $\left(1+K_{L} C\right)$, respectively, where $Q\left(\mathrm{mg} \mathrm{g}^{-1}\right)$ is the amount of adsorbed $\mathrm{Cu}(\mathrm{II})$ by FRGO and FGO, $\mathrm{C}\left(\mathrm{mg} \mathrm{L}^{-1}\right)$ is the equilibrium concentration in solution, $K_{\mathrm{f}}$ is an empirical constant related to adsorption capacity $\left(\mathrm{mg}^{(1-n)} \mathrm{g}^{-1} \mathrm{~L}^{n}\right), n$ is Freundlich exponent, $Q_{\max }$ is maximum adsorption capacity $\left(\mathrm{mg} \mathrm{g}^{-1}\right)$, and $\mathrm{K}_{\mathrm{L}}$ is adsorption equilibrium constant.

\section{Results and discussion}

\subsection{Characterization of FRGO and FGO}

The surface morphology of FRGO and FGO was characterized by SEM and TEM. It is found that both FRGO and FGO are closely agglomerated together as thin and randomly aggregated nanosheets (Fig. S3), and have typically wrinkled, sheet-like 
structures (Fig. S4). BET analysis shows that the specific surface areas ( $\left.A_{\mathrm{BET}}\right)$ of FRGO and FGO are 589.5 and $75.3 \mathrm{~m}^{2} \mathrm{~g}^{-1}$, respectively. The thickness and size of FRGO and FGO were measured by AFM (Fig. S5). The results show that the thickness of FRGO is $1.872 \mathrm{~nm}$, corresponding to about 5 layers of graphene, which is close to the calculated result (about 4.4 layers of graphene) using the scaling law: layer number $=2600 / A_{B E T}[30]$. The lateral length of FRGO is in the range of $0.3-1.2 \mu \mathrm{m}$. For FGO, its thickness is $1.158 \mathrm{~nm}$ (about 3 layers of graphene), and the lateral length is $0.7-2.0 \mu \mathrm{m}$.

XPS provides useful information about surface functional groups of FRGO and FGO. In Fig. 1a, the spectrum of FRGO shows a dominant peak of $\mathrm{sp}^{2} \mathrm{C}=\mathrm{C}$ at $284.6 \mathrm{eV}$, which was attributed to the graphitic structure. Several small peaks of $\mathrm{C}-\mathrm{O}$ at $285.9 \mathrm{eV}, \mathrm{C}=\mathrm{O}$ at $287.3 \mathrm{eV}$, and $\mathrm{O}-\mathrm{C}=\mathrm{O}$ at $288.9 \mathrm{eV}$ were assigned to carbon atoms attached to different oxygen-containing moieties. The spectrum of FGO shows three types of carbon bonds: the carbon $\mathrm{sp}^{2} \mathrm{C}=\mathrm{C}$ at $284.8 \mathrm{eV}$ in the basal plane of FGO, the carbon in $\mathrm{C}-\mathrm{O}$ at $286.8 \mathrm{eV}$ and the carbonyl carbon in $\mathrm{C}=\mathrm{O}$ at $288.5 \mathrm{eV}$ (Fig. 1b). These results indicated that the surface of FGO had large numbers of functional groups.

\subsection{Adsorption of HA on FRGO and FGO}

The adsorption of HA on FRGO and FGO as a function of $\mathrm{pH}$ is shown in Fig. 2. The results show that the adsorption of HA on both FRGO and FGO are $\mathrm{pH}$-dependent, where their adsorption capacities decrease as $\mathrm{pH}$ increases. Compared to FRGO, the $\mathrm{pH}$-dependency of HA adsorption on FGO is more pronounced. This suggests the primary contribution of polar interactions to the adsorption of HA, as FGO has higher density of polar groups (Fig. 1). With increasing solution $\mathrm{pH}$, the functional groups on both FGO/FRGO and HA become more deprotonated (Fig. S6), the electrostatic repulsion between them inhibits the adsorption of HA on FRGO and FGO, consistent with previous observations about HA adsorption on other adsorbents $[13,31]$.

In the examined $\mathrm{pH}$ range, it is found that FRGO showed much larger adsorption capacity compared to that of FGO. This is possibly because the relatively lower surface area of FGO does not provide sufficient adsorption sites for HA. Interestingly, in terms of surface area normalized adsorption capacity, the adsorption of HA on FGO was higher than that on FRGO at $\mathrm{pH}<6.5$ (Fig. S7), which was opposite to the trend

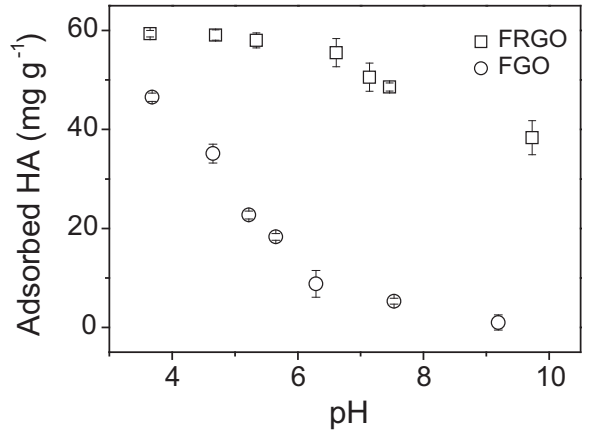

Fig. 2 - Adsorption of HA on FRGO and FGO as a function of solution pH. Initial concentration of HA was $30.0 \mathrm{mg} \mathrm{L}^{-1}$ in $0.01 \mathrm{M} \mathrm{NaNO}_{3}$ solution. Data are means of three separate experiments. Error bars represent standard deviation.

shown in Fig. 2. Considering the different surface properties of FRGO and FGO, it is significant that HA was adsorbed on FRGO and FGO with different adsorption mechanisms. FRGO has rich $\pi$ electrons and hydrophobic surface. It is speculated that $\pi-\pi$ interaction and/or hydrophobic interaction are the main driving force [12]. Compared to FRGO, FGO contains fewer $\pi$-electrons, but more O-containing groups on its surfaces. It is possible that HA is adsorbed on FGO through polar interactions with these functional groups of FGO.

To reveal the adsorption mechanisms of HA on FRGO and FGO, a $\mu$-FTIR study was performed (Fig. 3). For FRGO, peak at $1581 \mathrm{~cm}^{-1}$ was assigned to benzene ring $\mathrm{C}=\mathrm{C}$ stretching vibration (Fig. 3a). Peaks that appeared at 1734 and $1245 \mathrm{~cm}^{-1}$ were the results of carboxyl $\mathrm{C}=\mathrm{O}$ and epoxy $\mathrm{C}-\mathrm{O}$ stretching vibrations, respectively. For HA, peak at $3367 \mathrm{~cm}^{-1}$ was assigned to the $-\mathrm{OH}$ stretching vibration. The shoulder peak at $1713 \mathrm{~cm}^{-1}$ was assigned to the $\mathrm{C}=\mathrm{O}$ stretch of $-\mathrm{COOH}$ group, and the peak at $1632 \mathrm{~cm}^{-1}$ corresponded to the aromatic $\mathrm{C}=\mathrm{C}$ stretching vibration and the ketone $\mathrm{C}=\mathrm{O}$ stretching vibration of HA [32,33]. When HA was adsorbed on FRGO (Fig. 3d), it was found that the peaks of HA attributable to hydroxyl group $\left(3367 \mathrm{~cm}^{-1}\right)$ and to carboxyl group $\left(1713 \mathrm{~cm}^{-1}\right)$ exhibited no significant shift, suggesting that these polar groups were not involved in adsorption. As a result, the shift of peak at 1632 to $1596 \mathrm{~cm}^{-1}$ can be attributed to the occurrence of $\pi-\pi$ interaction between aromatic moiety of HA and FRGO surface. It is noticeable that $\pi-\pi$ interaction weakens the double band character of aromatic rings of HA and causes a
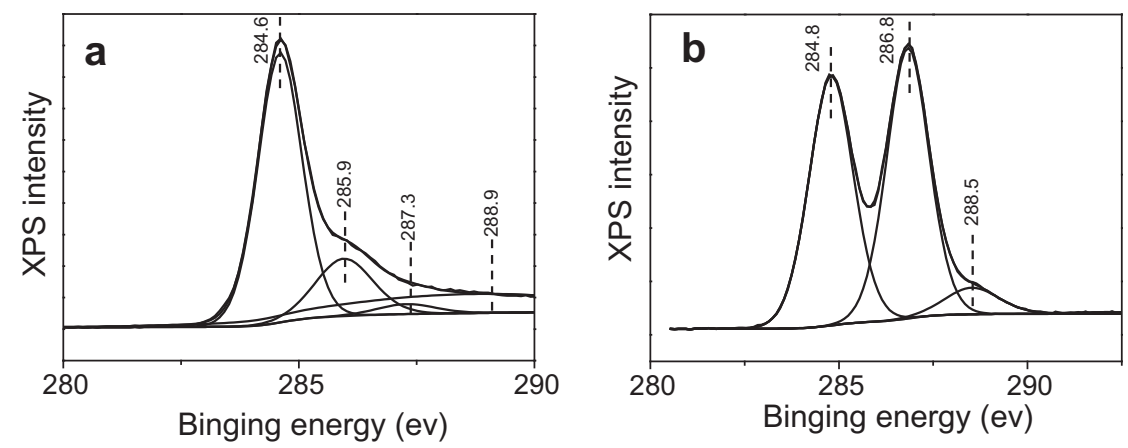

Fig. 1 - C1s XPS spectra of FRGO (a) and FGO (b). 


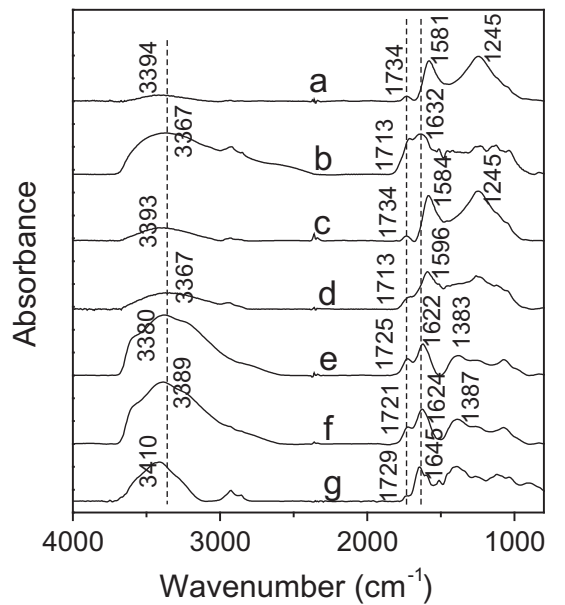

Fig. 3 - $\mu$-FTIR spectra of FRGO (a), HA (b), HA-adsorbed FRGO (c), difference spectrum of HA adsorbed on FRGO (d), FGO (e), HA-adsorbed FGO (f), and difference spectrum of HA adsorbed on FGO (g).

red-shift of $\mathrm{C}=\mathrm{C}$ stretching vibration bands (Fig. 3d). This finding is supported by Hyung and Kim [12], who indicated that $\pi-$ $\pi$ interaction was the main driving force for the adsorption of natural organic matter on multi-walled carbon nanotubes. Furthermore, when HA is adsorbed on FRGO through $\pi-\pi$ interaction, the hydrophobic surface of FRGO will be shielded by the aromatic moiety of HA, leaving the polar moiety of HA (carboxyl and phenolic groups, etc.) free in the opposite direction. The EMPs results revealed that ionization of these adsorbed HA further increased the surface negatively charged density of FRGO (Fig. S6a). As a result, the adsorbed HA enhanced the steric and electrostatic stabilization of FRGO and facilitated the dispersion of FRGO in aqueous solution. As shown in Fig. S8, suspension of FRGO alone became transparent quickly after settling. When HA and FRGO were mixed together, it is found the aqueous solution appeared dark and turbid even after settling for 4 days, suggesting FRGO remained suspending in solution in the presence of HA.

Compared to FRGO, $\mu$-FTIR results reveal that HA has different adsorption mechanism on FGO due to its less $\pi$ electron density and rich O-containing functional groups. For FGO, the broad peak at $3380 \mathrm{~cm}^{-1}$ corresponded to $-\mathrm{OH}$ stretching vibration (Fig. 3e). In low wavenumbers range, FTIR spectra of FGO showed carboxyl $\mathrm{C}=\mathrm{O}\left(1725 \mathrm{~cm}^{-1}\right)$, aromatic $\mathrm{C}=\mathrm{C}$ $\left(1622 \mathrm{~cm}^{-1}\right)$, and carboxyl $\mathrm{O}=\mathrm{C}-\mathrm{O}\left(1383 \mathrm{~cm}^{-1}\right)$ stretching vibrations. When HA was adsorbed on FGO (Fig. 3f), the bands of FGO at 3380 and $1725 \mathrm{~cm}^{-1}$ were shifted to 3389 and $1721 \mathrm{~cm}^{-1}$, suggesting the interaction between HA and FGO. The difference spectrum of HA adsorbed on FGO was shown in Fig. $3 g$, where the $-\mathrm{OH}$ stretching vibration, carboxyl $\mathrm{C}=\mathrm{O}$ and ketone $\mathrm{C}=\mathrm{O}$ stretching vibration of $\mathrm{HA}$ shifted significantly from 3367, 1713 and 1632 to 3410, 1729 and $1645 \mathrm{~cm}^{-1}$, respectively, indicating that these polar functional groups were involved in the adsorption of HA on FGO [34,35].

The effect of HA on the electrokinetic properties of FGO is reported in Fig. S6. It is shown that the increase of HA concentrations had a negligible effect on the EMPs of FGO, consistent with the result of Chowdhury et al. [36]. Addition of HA, however, enhanced the stabilization of FGO in water (Fig. S8). Because HA did not affect the EMPs of FGO, steric repulsion imparted by the adsorbed HA macromolecules may be the dominant mechanism in FGO stabilization $[36,37]$.

\subsection{Effects of $\mathrm{HA}$ on $\mathrm{Cu}(\mathrm{II})$ adsorption}

Adsorption isotherms of $\mathrm{Cu}(\mathrm{II})$ on FRGO and FGO in the absence and presence of HA are shown in Fig. 4. Freundlich and Langmuir models were applied to fit the adsorption data. At the $95 \%$ confidence interval, it was found that the $R^{2}$ values of the Langmuir model were higher than those of the Freundlich model, indicating that the Langmuir model fitted the adsorption data better than the Freundlich model (Table 1). The $Q_{\max }$ values of $\mathrm{Cu}(\mathrm{II})$ adsorption on FRGO and FGO in the absence of HA were 11.40 and $73.36 \mathrm{mg} \mathrm{g}^{-1}$ (Table 1), respectively, suggesting that FGO was a more effective adsorbent for $\mathrm{Cu}$ (II) due to its numerous O-containing functional groups $[17,19]$. Table S3 shows the amount of different O-containing functional groups (such as carboxyl, lactone, and hydroxyl groups) on FGO. It was found that the content of carboxyl groups was higher than the sum of lactone and hydroxyl groups. Considering the strong complexation capability of carboxyl groups, it was possible that carboxyl groups played a more important role in $\mathrm{Cu}(\mathrm{II})$ adsorption than other O-containing functional groups.

When HA was added, it was found that the adsorption of $\mathrm{Cu}$ (II) on FRGO increased with increasing initial HA concentrations from 0 to $30.0 \mathrm{mg} \mathrm{L}^{-1}$, suggesting that $\mathrm{HA}$ facilitated the adsorption of $\mathrm{Cu}$ (II) on FRGO (Fig. $4 \mathrm{a}$ ). $\mathrm{Q}_{\max }$ was used to compare the adsorption of $\mathrm{Cu}(\mathrm{II})$ (Table 1). Obviously, $\mathrm{Q}_{\max }$ values increased from 11.40 to $18.60 \mathrm{mg} \mathrm{g}^{-1}$ when HA concentrations increased from 0 to $30.0 \mathrm{mg} \mathrm{L}^{-1}$. As mentioned above, HA was adsorbed on FRGO mainly through $\pi-\pi$ interaction between the aromatic fractions of $\mathrm{HA}$ and the aromatic surfaces of FRGO, leaving O-containing functional groups (carboxyl and phenolic groups, etc.) of HA available. Undoubtedly, the adsorbed HA introduced more O-containing functional groups and negative charges to FRGO surface, increasing the adsorption of $\mathrm{Cu}$ (II) through chemical complexation and electrostatic attraction. In addition, the adsorbed HA increased FRGO dispersion in solution and made more adsorption sites on FRGO available (Fig. S8), which also facilitated the adsorption of $\mathrm{Cu}(\mathrm{II})$ on FRGO to some extent.

Compared to FRGO, the presence of HA had little effects on the adsorption of $\mathrm{Cu}$ (II) on FGO (Fig. 4b), despite much HA had been adsorbed on FGO at pH 5.0 (Fig. 2). To date, very limited studies were available regarding the effects of HA on metal adsorption on FGO $[17,38]$. As mentioned above, HA was adsorbed on FGO through polar interactions. Obviously, these adsorbed HA shielded the surface of FGO and occupied parts of surface sites on FGO, which would decrease the adsorption of $\mathrm{Cu}(\mathrm{II})$. Meanwhile, the adsorption of HA also introduced new adsorption sites for metal adsorption because HA had various functional groups that can bind $\mathrm{Cu}(\mathrm{II})$ [39]. Depending on the properties of used HAs, HAs could impart different effects on metal adsorption on FGO $[17,38]$. For example, Zhao et al. [17] suggested that HA with high aromatic content (57.0\%) effectively shielded the FGO surface with its aromatic moiety, and decreased the adsorption of cadmium and cobalt 

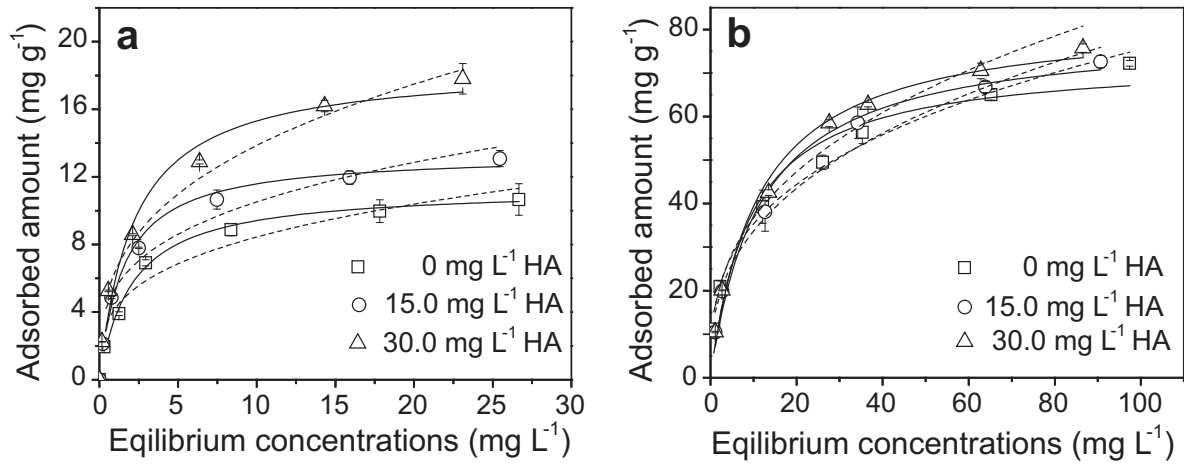

Fig. 4 - Adsorption isotherms of Cu(II) on FRGO (a) and FGO (b) in the absence and presence of different concentrations of HA in $0.01 \mathrm{M} \mathrm{NaNO}_{3}$ background electrolyte at $\mathrm{pH} 5.0 \pm 0.1$. Data are means of three separate experiments. Error bars represent standard deviation. The solid lines are Langmuir model simulation, and the dashed lines are Freundlich model simulation.

\begin{tabular}{|c|c|c|c|c|c|c|}
\hline \multirow[t]{2}{*}{ HA concentrations $\left(\mathrm{mg} \mathrm{L}^{-1}\right)$} & \multicolumn{3}{|c|}{ Langmuir } & \multicolumn{3}{|c|}{ Freundlich } \\
\hline & $\mathrm{Q}_{\max }$ & $K_{\mathrm{L}}$ & $R^{2}$ & $K_{\mathrm{f}}$ & $n$ & $R^{2}$ \\
\hline \multicolumn{7}{|l|}{ FRGO } \\
\hline 0 & 11.40 & 0.49 & 0.99 & 4.23 & 0.30 & 0.93 \\
\hline 15.0 & 13.40 & 0.65 & 0.99 & 5.40 & 0.29 & 0.95 \\
\hline 30.0 & 18.60 & 0.46 & 0.97 & 6.40 & 0.34 & 0.98 \\
\hline \multicolumn{7}{|l|}{ FGO } \\
\hline 0 & 73.36 & 0.11 & 0.97 & 16.58 & 0.33 & 0.95 \\
\hline 15.0 & 79.64 & 0.09 & 0.98 & 14.43 & 0.37 & 0.98 \\
\hline 30.0 & 82.91 & 0.09 & 0.99 & 15.84 & 0.37 & 0.97 \\
\hline
\end{tabular}

on FGO. In our case, the aromatic and carboxylic contents of the HA are $36.6 \%$ and $13.1 \%$, respectively. No striking changes in $\mathrm{Cu}(\mathrm{II})$ adsorption on FGO by HA coating indicated that the shielding effect of HA on $\mathrm{Cu}$ (II) adsorption was offset by the newly introduced adsorption sites of HA on FGO (Fig. 4). To further verify this conclusion, we chose fulvic acid (FA) to study the effect of FA on $\mathrm{Cu}$ (II) adsorption on FGO. Compared to HA, FA has higher polarity, lower aromaticity and is more hydrophilic (Table S1) [38]. As shown in Fig. S9, the presence of FA increased the adsorption of $\mathrm{Cu}$ (II) on FGO, suggesting that FA increased the adsorption sites on FGO surface and facilitated the adsorption of $\mathrm{Cu}$ (II).

It is possible that solution $\mathrm{pH}$ may affect the surface charge of adsorbents and the ionic species of metals. Therefore, the adsorption of $\mathrm{Cu}$ (II) on FRGO and FGO with or without $\mathrm{HA}$ at different equilibrium solution $\mathrm{pH}$ were also studied (Fig. 5). In the single solute system, it is observed that adsorption of $\mathrm{Cu}$ (II) increased at $\mathrm{pH} 4.0-7.5$, and then maintained high loading level at $\mathrm{pH}>7.5$ (Fig. 5). The $\mathrm{pH}$ dependence of adsorption reactions of $\mathrm{Cu}$ (II) was due, in part, to the
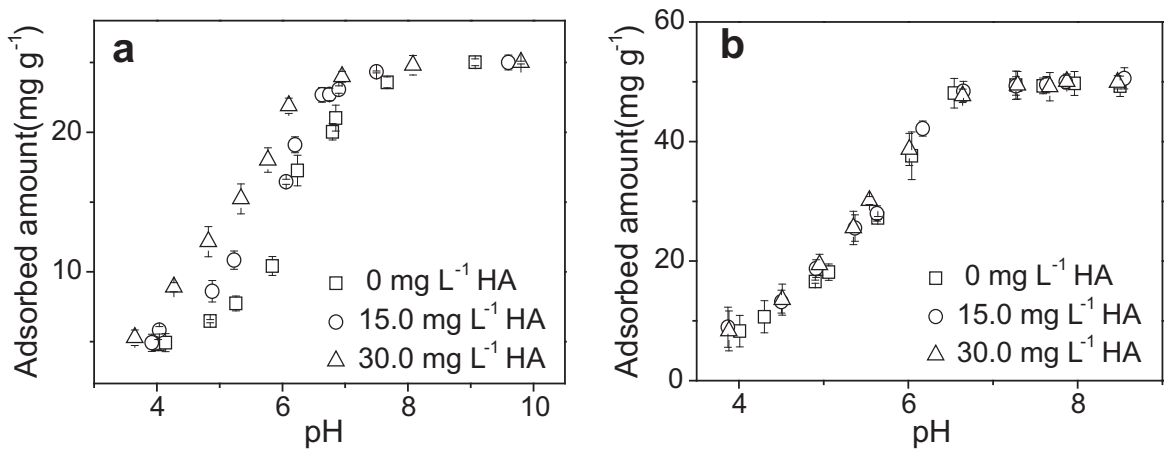

Fig. 5 - Effect of pH on Cu(II) adsorption on FRGO (a) and FGO (b) in the absence and presence of different concentrations of HA. Initial concentrations of $\mathrm{Cu}$ (II) was $0.2 \mathrm{mM}$ in $0.01 \mathrm{M} \mathrm{NaNO}_{3}$ background electrolyte. Data are means of three separate experiments. Error bars represent standard deviation. 
preferential adsorption of hydrolyzed $\mathrm{Cu}(\mathrm{II})$ species in comparison to free $\mathrm{Cu}$ ion [40]. Another reason was that an increase of solution $\mathrm{pH}$ increased the number of negatively charged sites on FRGO and FGO, which further promoted the adsorption of cationic $\mathrm{Cu}(\mathrm{II})$ (Fig. S6). When HA was added, it was found that HA increased the adsorption of $\mathrm{Cu}$ (II) significantly at $\mathrm{pH}<8.0$ on FRGO. At $\mathrm{pH}$ above 8.0, HA had little effect on the adsorbed amount of $\mathrm{Cu}$ (II) on FRGO (Fig. 5a). In comparison, the presence of HA had negligible effects on the adsorption of $\mathrm{Cu}$ (II) on $\mathrm{FGO}$ over the entire $\mathrm{pH}$ range (Fig. 5b).

\subsection{EXAFS analysis}

EXAFS was used to identify the surface complexation and the coordination environment of adsorbed Cu(II) on FRGO and FGO. Identification of such complex formation provides an insight into the adsorption mechanisms and species of $\mathrm{Cu}(\mathrm{II})$. The $k^{3}$-weighted EXAFS spectra for the adsorbed $\mathrm{Cu}$ (II) on FRGO and FGO at pH 4.0, 6.0 and 8.0, and reference sample of aqueous $\mathrm{Cu}$ (II) ions are presented in Fig. 6a. Except sample FRGO at pH 8.0, it was found that spectra of all samples were dominated by a single sinusoidal wave mainly from the backscattering off of $\mathrm{O}$ atoms in the first atomic shell.

The corresponding radial structure functions (RSFs) are shown in Fig. 6b. For all adsorbed samples, two peaks were observed in the RSF spectra at $\sim 1.5$ and $\sim 2.5 \AA$. The first peak in the RSF spectra occurring at $\sim 1.5 \AA$ corresponds to the backscattering oxygen atoms of the first shell. When $\mathrm{Cu}$ (II) was adsorbed on FRGO without $\mathrm{HA}$ at $\mathrm{pH} 4.0$ and 6.0, the EXAFS fitting reveals that the $\mathrm{Cu}-\mathrm{O}$ shell consists of 3.90 and $4.01 \mathrm{O}$ atoms at an effective $\mathrm{Cu}-\mathrm{O}$ distance of $1.94 \AA$
(Table 2). The second peak at $\sim 2.5 \AA$ is evidenced from $\mathrm{Cu}-\mathrm{C}$ backscatter. The best fit of the second shell leads to 2.32 and 3.0 C atoms at a bond distance of 2.92 and $2.91 \AA$, respectively, suggesting that $\mathrm{Cu}$ (II) was adsorbed on FRGO surfaces mainly through the coordination with O-containing functional groups of FRGO rather than Lewis acid-base interaction [23]. When solution $\mathrm{pH}$ was increased to 8.0 (Fig. 6b), the magnitude of the second peak (at $\sim 2.5 \AA$ ) increased. Compared to that at $\mathrm{pH} 4.0$ and 6.0, it is found that this peak is a combination of $\mathrm{Cu}-\mathrm{C}$ and $\mathrm{Cu}-\mathrm{Cu}$ backscatter, including $7.0 \mathrm{C}$ atoms at a bond distance of $2.90 \AA$, and $3.60 \mathrm{Cu}$ (II) atoms at a bond distance of $2.92 \AA$ (Table 2). The $\mathrm{Cu}-\mathrm{Cu}$ bond distance is very close to that in $\mathrm{Cu}(\mathrm{OH})_{2}$ [41]. Therefore, it is speculated that a portion of $\mathrm{Cu}$ may precipitate from aqueous solution onto FRGO surface at high $\mathrm{pH}$ range.

When $\mathrm{Cu}(\mathrm{II})$ was adsorbed on FRGO in the presence of HA at $\mathrm{pH} 4.0$ and 6.0 , the fitting results showed that the coordinated $\mathrm{C}$ atom numbers of the second peak increased from 2.32 and 3.0 to 3.31 and 3.80 , suggesting that more $\mathrm{Cu}$ (II) was adsorbed on the coated HA (Table 2). When solution $\mathrm{pH}$ was increased to 8.0, interestingly, it was found that the intensity of the second peak at $2.5 \AA$ decreased compared to that in the absence of HA (Fig. 6). The second shell was best fitted with $3.60 \mathrm{C}$ atoms at an average distance of $2.94 \AA$ (Table 2). This result indicated that the adsorbed HA increased the amount of adsorption sites on FRGO and caused most of $\mathrm{Cu}$ (II) to be adsorbed as FRGO-HA-Cu ternary surface complexes rather than precipitation.

When $\mathrm{Cu}$ (II) was adsorbed on FGO without HA, it is found that an increase of solution $\mathrm{pH}$ had little effect on these RSF spectra (Fig. 6). Fitting results show that $\sim 3.7 \mathrm{O}$ atoms at a bond distance of $\sim 1.94 \AA$ occur in the first shell peak and
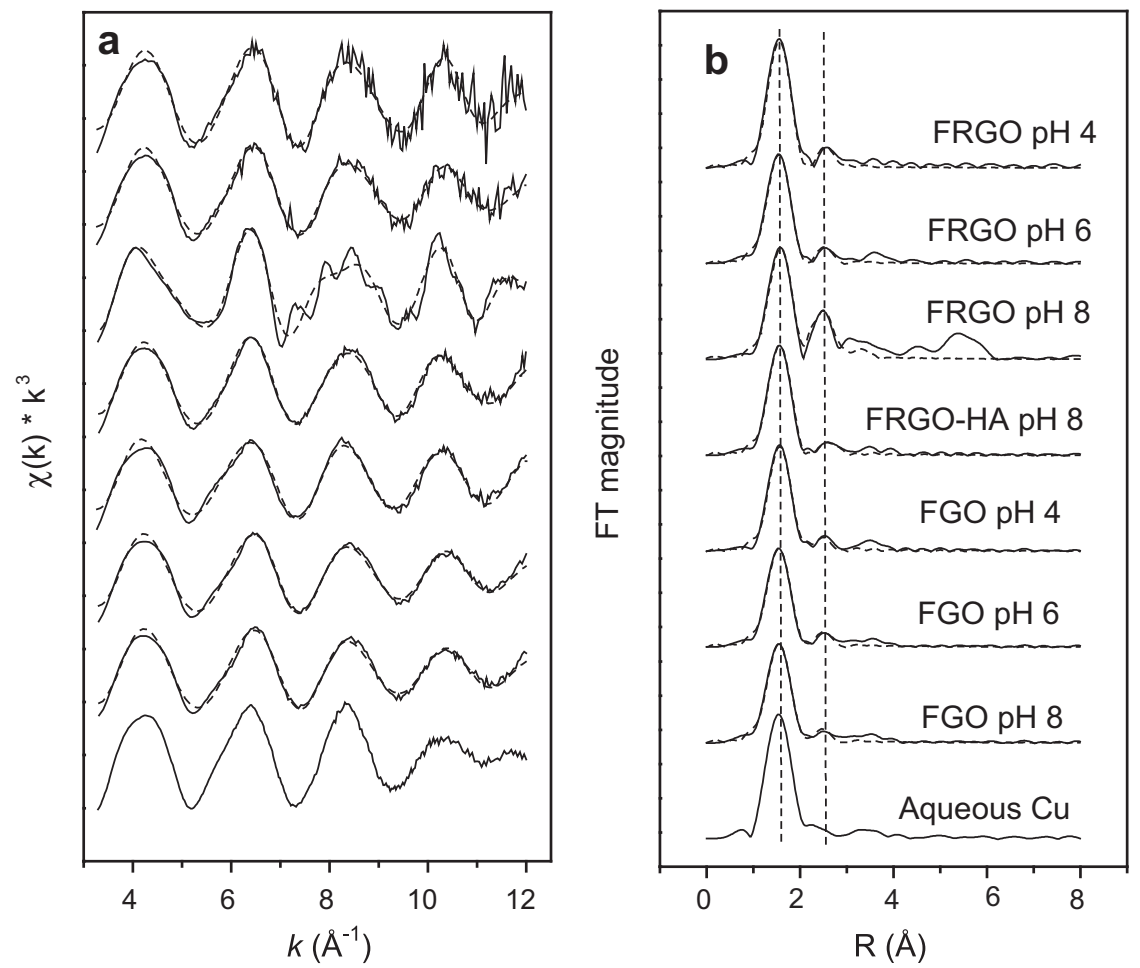

Fig. 6 - Raw (solid) and fitted (dashed) EXAFS spectra ( $\chi$-function) (a) and Fourier transformation of EXAFS spectra (b) for the adsorbed $\mathrm{Cu}$ (II) on FRGO and FGO at $\mathrm{pH} 4.0,6.0$ and 8.0, and $\mathrm{Cu}$ (II) reference compound of aqueous $\mathrm{Cu}\left(\mathrm{NO}_{3}\right)_{2}$. 
Table 2 - EXAFS fitting results for adsorbed $\mathrm{Cu}$ on FRGO and FGO in the absence and presence of HA.

\begin{tabular}{|c|c|c|c|c|c|c|c|c|c|}
\hline \multirow[t]{2}{*}{ Samples } & \multicolumn{3}{|c|}{ Cu-O shell } & \multicolumn{3}{|c|}{$\mathrm{Cu}-\mathrm{C}$ shell } & \multicolumn{3}{|c|}{$\mathrm{Cu}-\mathrm{Cu}$ shell } \\
\hline & $\begin{array}{l}R(\AA)^{\mathrm{a}} \\
( \pm 0.02)\end{array}$ & $\begin{array}{l}N^{\mathrm{b}} \\
( \pm 20 \%)\end{array}$ & $\begin{array}{l}\sigma^{2}\left(\AA^{2}\right)^{c} \\
( \pm 0.0005)\end{array}$ & $\begin{array}{l}R(\AA)^{a} \\
( \pm 0.02)\end{array}$ & $\begin{array}{l}N^{\mathrm{b}} \\
( \pm 20 \%)\end{array}$ & $\begin{array}{l}\sigma^{2}\left(\AA^{2}\right)^{c} \\
( \pm 0.0005)\end{array}$ & $\begin{array}{l}R(\AA)^{a} \\
( \pm 0.02)\end{array}$ & $\begin{array}{l}N^{\mathrm{b}} \\
( \pm 20 \%)\end{array}$ & $\begin{array}{l}\sigma^{2}\left(\AA^{2}\right)^{c} \\
( \pm 0.0005)\end{array}$ \\
\hline \multicolumn{10}{|l|}{ FRGO } \\
\hline pH 4.0 & 1.94 & 3.90 & 0.003 & 2.92 & 2.32 & 0.006 & & & \\
\hline pH 6.0 & 1.94 & 4.01 & 0.005 & 2.91 & 3.00 & 0.007 & & & \\
\hline pH 8.0 & 1.95 & 4.20 & 0.004 & 2.90 & 7.00 & 0.008 & 2.92 & 3.60 & 0.01 \\
\hline \multicolumn{10}{|l|}{ FRGO-HA } \\
\hline pH 4.0 & 1.94 & 3.80 & 0.004 & 2.91 & 3.31 & 0.01 & & & \\
\hline pH 6.0 & 1.94 & 3.88 & 0.005 & 2.90 & 3.80 & 0.01 & & & \\
\hline pH 8.0 & 1.95 & 3.90 & 0.004 & 2.94 & 3.60 & 0.009 & & & \\
\hline \multicolumn{10}{|l|}{ FGO } \\
\hline pH 4.0 & 1.95 & 3.58 & 0.003 & 2.90 & 2.52 & 0.006 & & & \\
\hline pH 6.0 & 1.94 & 3.76 & 0.005 & 2.92 & 3.43 & 0.010 & & & \\
\hline pH 8.0 & 1.94 & 3.82 & 0.005 & 2.91 & 2.92 & 0.011 & & & \\
\hline \multicolumn{10}{|l|}{ FGO-HA } \\
\hline $\mathrm{pH} 4.0$ & 1.95 & 3.57 & 0.003 & 2.90 & 2.69 & 0.009 & & & \\
\hline pH 6.0 & 1.94 & 3.78 & 0.004 & 2.90 & 3.45 & 0.011 & & & \\
\hline $\mathrm{pH} 8.0$ & 1.94 & 3.84 & 0.004 & 2.92 & 3.17 & 0.009 & & & \\
\hline $\begin{array}{l}\text { Blank cells } \\
\text { a Bond dis } \\
\text { b Coordina } \\
{ }^{c} \text { Debye W }\end{array}$ & $\begin{array}{l}\text { data. Esti } \\
\text { es. } \\
\text { number. } \\
\text { factor. }\end{array}$ & ed standa & eviations of & least squ & tting rout & are given in & entheses. & & \\
\hline
\end{tabular}

3.0 C atoms at a bond distance of $2.91 \AA$ occur in the second shell peak (Table 2). Compared to FRGO, the RSF spectra of adsorbed $\mathrm{Cu}$ (II) on FGO at pH 8.0 was significantly different, where the second peak mainly arose from $\mathrm{Cu}-\mathrm{C}$ backscatter. The results suggest that most of $\mathrm{Cu}(\mathrm{II})$ in solution was adsorbed on FGO surfaces instead of precipitation because more adsorption sites were available on GO surfaces. The complexation information of $\mathrm{Cu}$ (II) on FGO in the presence of HA was also examined (Table 2). It is found that the fitting data are similar to that without $\mathrm{HA}$, suggesting that $\mathrm{Cu}$ (II) was adsorbed through the coordination with O-containing functional groups. However, it was difficult to distinguish these functional groups from FGO or from the coated HA by EXAFS alone.

\section{Conclusions}

The present study showed HA was adsorbed on both FRGO and FGO through different mechanisms, and consequently exerted different effects on the adsorption of $\mathrm{Cu}$ (II) on FRGO and FGO. The results suggested that HA was adsorbed on FRGO mainly through $\pi-\pi$ interaction. The adsorbed HA introduced O-containing functional groups and negative charges to FRGO surface, increasing the adsorption of $\mathrm{Cu}$ (II) through complexation and electrostatic attraction. While HA was adsorbed on FGO through polar interactions. On the one hand, these adsorbed HA shielded the surface of FGO and occupied parts of surface sites on FGO, which would decrease the adsorption of $\mathrm{Cu}$ (II). On the other hand, the adsorbed HA can introduce new adsorption sites for $\mathrm{Cu}$ (II) adsorption onto the FGO surface. Depending on the properties of HA, HA could impart different effects on $\mathrm{Cu}$ (II) adsorption on FGO. In this study, the results suggest that $\mathrm{HA}$ had little effect on $\mathrm{Cu}$ (II) adsorption onto FGO. EXAFS results suggest that O-containing functional groups of FRGO and FGO were the main adsorption sites for $\mathrm{Cu}$ (II). Compared to FGO, FRGO had fewer O-containing functional groups on its surfaces, which led to a portion of $\mathrm{Cu}$ (II) precipitate on FRGO surfaces at $\mathrm{pH}$ 8.0. The addition of HA increased the amount of adsorption sites on FRGO, causing most of $\mathrm{Cu}$ (II) to be adsorbed on FRGO surfaces as FRGO-HA-Cu ternary surface complexes at the examined $\mathrm{pH}$ range.

\section{Acknowledgments}

This work was funded by National Natural Science Foundation of China (21277159), National Key Basic Research Program of China (973 Program) (2014CB441102), and National Natural Science Foundation of China (41071308). The authors thank Mr. Michael Nguyen for his improvement of the English in this manuscript.

\section{Appendix A. Supplementary data}

Supplementary data associated with this article can be found, in the online version, at http://dx.doi.org/10.1016/j.carbon. 2014.03.057.

\section{R E F E R E N C E S}

[1] Novoselov KS, Geim AK, Morozov SV, Jiang D, Zhang Y, Dubonos SV. Electric field effect in atomically thin carbon films. Science 2004;306:666-9.

[2] Zhao GX, Jiang L, He YD, Li JX, Dong HL, Wang XK. Sulfonated graphene for persistent aromatic pollutant management. Adv Mater 2011;23:3959-63. 
[3] Wu T, Cai X, Tan SZ, Li HY, Liu JS, Yang WD. Adsorption characteristics of acrylonitrile, p-toluenesulfonic acid, 1naphthalene sulfonic acid and methyl blue on graphene in aqueous solutions. Chem Eng J 2011;173:144-9.

[4] Ramesha GK, Vijaya KA, Muralidhara HB, Sampath S. Graphene and graphene oxide as effective adsorbents toward anionic and cationic dyes. J Colloid Interface Sci 2011;361:270-7.

[5] Chandra V, Park J, Chun Y, Lee JW, Hwang IC, Kim KS. Waterdispersible magnetite-reduced graphene oxide composites for arsenic removal. ACS Nano 2010;4:3979-86.

[6] Mishra AK, Ramaprabhu S. Functionalized graphene sheets for arsenic removal and desalination of sea water. Desalination 2011;282:39-45.

[7] Chandra V, Kim KS. Highly selective adsorption of $\mathrm{Hg}^{2+}$ by a polypyrrole-reduced graphene oxide composite. Chem Commun 2011;47:3942-4.

[8] Kozlov SM, Vines F, Görling A. On the interaction of polycyclic aromatic compounds with graphene. Carbon 2012;50(7):2482-92.

[9] Sanchez VC, Jachak A, Hurt RH, Kane AB. Biological interactions of graphene-family nanomaterials: an interdisciplinary review. Chem Res Toxicol 2012;25: 15-34.

[10] Yang K, Xing BS. Sorption of phenanthrene by humic acidcoated nanosized $\mathrm{TiO}_{2}$ and $\mathrm{ZnO}$. Environ Sci Technol 2009;43:1845-51.

[11] Tian XL, Li TT, Yang K, Xu Y, Lu HF, Lin DH. Effect of humic acids on physicochemical property and Cd(II) sorption of multiwalled carbon nanotubes. Chemosphere 2012;89:1316-22.

[12] Hyung H, Fortner JD, Hughes JB, Kim JH. Natural organic matter stabilizes carbon nanotubes in the aqueous phase. Environ Sci Technol 2007;41:179-84.

[13] Hyung H, Kim JH. Natural organic matter (NOM) adsorption to multiwalled carbon nanotubes: effect of NOM characteristics and water quality parameters. Environ Sci Technol 2008;42:4416-21.

[14] Gai K, Shi BY, Yan XM, Wang DS. Effect of dispersion on adsorption of atrazine by aqueous suspensions of fullerenes. Environ Sci Technol 2011;45:5959-65.

[15] Chen QQ, Yin DQ, Zhu SJ, Hu XL. Adsorption of cadmium(II) on humic acid coated titanium dioxide. J Colloid Interface Sci 2012;367:241-8

[16] Liu JF, Zhao ZS, Jiang GB. Coating $\mathrm{Fe}_{3} \mathrm{O}_{4}$ magnetic nanoparticles with humic acid for high efficient removal of heavy metals in water. Environ Sci Technol 2008;42:6949-54.

[17] Zhao G, Li JX, Ren XM, Chen CL, Wang XK. Few-layered graphene oxide nanosheets as superior sorbents for heavy metal ion pollution management. Environ Sci Technol 2011;45:10454-62.

[18] Yang ST, Chang YL, Wang HF, Liu GB, Chen S, Wang YW, et al. Folding/aggregation of graphene oxide and its application in $\mathrm{Cu}^{2+}$ removal. J Colloid Interface Sci 2010;351:122-7.

[19] Sun YB, Wang Q, Chen CL, Tan XL, Wang XK. Interaction between Eu(III) and graphene oxide nanosheets investigated by batch and extended X-ray absorption fine structure spectroscopy and by modeling techniques. Environ Sci Technol 2012;46:6020-7.

[20] Deng XJ, Lv LL, Li HW, Luo F. The adsorption properties of $\mathrm{Pb}$ (II) and $\mathrm{Cd}$ (II) on functionalized graphene prepared by electrolysis method. J Hazard Mater 2010;183:923-30.

[21] Gao W, Majumder M, Alemany LB, Narayanan TN, Ibarra MA, Pradhan BK, et al. Engineered graphite oxide materials for application in water purification. ACS Appl Mater Interfaces 2011;3:1821-6.
[22] Madadrang CJ, Kim HY, Gao GH, Wang N, Zhu J, Feng H, et al. Adsorption behavior of EDTA-graphene oxide for $\mathrm{Pb}$ (II) removal. ACS Appl Mater Interfaces 2012;4:1186-93.

[23] Huang ZH, Zheng XY, Lv W, Wang M, Yang QH, Kang FY. Adsorption of lead(II) ions from aqueous solution on lowtemperature exfoliated graphene nanosheets. Langmuir 2011;27:7558-62.

[24] Chen CM, Yang QH, Yang YG, Lv W, Wen YF, Hou PX, et al. Self-assembled free-standing graphite oxide membrane. Adv Mater 2009;21:3007-11.

[25] Chen CM, Zhang Q, Yang MG, Huang CH, Yang YG, Wang MZ Structural evolution during annealing of thermally reduced graphene nanosheets for application in supercapacitors. Carbon 2012;50:3572-84.

[26] Swift RS. Organic matter characterization. In: Sparks DL, editor. Methods of soil analysis. Part 3. Chemical methods. Soil Sci. Soc. Am. Book Series, vol. 5. Madison, WI: SSSA; 1996. p. 1018-20.

[27] Boehm HP. Some aspects of the surface chemistry of carbon blacks and other carbons. Carbon 1994;32:759-69.

[28] Boehm HP. Surface oxides on carbon and their analysis: a critical assessment. Carbon 2002;40:145-9.

[29] Zabinsky SI, Rehr JJ, Ankudinov A, Albers RC, Eller MJ. Multiple-scattering calculations of X-ray absorption spectra. Phys Rev B 1995;52:2995-3009.

[30] Guo F, Creighton M, Chen YT, Hurt R, Külaots I. Porous structures in stacked, crumpled and pillared graphene-based 3D materials. Carbon 2014;66:476-84.

[31] Li FS, Yuasa A, Ebie K, Azuma Y, Hagishita T, Matsui Y. Factors affecting the adsorption capacity of dissolved organic matter onto activated carbon: modified isotherm analysis. Water Res 2002;36:4592-604.

[32] Pérez MG, Martin-Neto L, Saab SC, Novotny EH, Milori D, Bagnato VS, et al. Characterization of humic acids from a Brazilian Oxisol under different tillage systems by EPR, ${ }^{13} \mathrm{C}$ NMR, FTIR and fluorescence spectroscopy. Geoderma 2004;118:181-90.

[33] Amir S, Jouraiphy A, Meddich A, Gharous ME, Winterton P, Hafidi M. Structural study of humic acids during composting of activated sludge-green waste: elemental analysis, FTIR and ${ }^{13} \mathrm{C}$ NMR. J Hazard Mater 2010;177:524-9.

[34] Hartono T, Wang SB, Ma Q Zhu ZH. Layer structured graphite oxide as a novel adsorbent for humic acid removal from aqueous solution. J Colloid Interface Sci 2009;333:114-9.

[35] Lin-Vien D, Colthup NB, Fateley WG, Grasselli JG. The handbook of infrared and raman characteristic frequencies of organic molecules. New York: Academic; 1991.

[36] Chowdhury I, Duch MC, Mansukhani ND, Hersam MC, Bouchard D. Colloidal properties and stability of graphene oxide nanomaterials in the aquatic environment. Environ Sci Technol 2013;47:6288-96.

[37] Fu HY, Zhu DQ. Graphene oxide-facilitated reduction of nitrobenzene in sulfide-containing aqueous solutions. Environ Sci Technol 2013;47:4204-10.

[38] Li J, Zhang SW, Chen CL, Zhao GX, Yang X, Li JX, et al. Removal of $\mathrm{Cu}(\mathrm{II})$ and fulvic acid by graphene oxide nanosheets decorated with $\mathrm{Fe}_{3} \mathrm{O}_{4}$ nanoparticles. ACS Appl Mater Interfaces 2012;4:4991-5000.

[39] Wang XL, Lu JL, Xing BS. Sorption of organic contaminants by carbon nanotubes: influence of adsorbed organic matter. Environ Sci Technol 2008;42:3207-12.

[40] McLean JE, Eledsoe BE. Behavior of metals in soils. Ground water issue, EPA/540/S-92/018; The United States Environmental Protection Agency: Washington, DC; 1992.

[41] Cheah SF, Brown Jr GE, Parks GA. XAFS study of Cu model compounds and $\mathrm{Cu}^{2+}$ sorption products on amorphous $\mathrm{SiO}_{2}$, $\gamma-\mathrm{Al}_{2} \mathrm{O}_{3}$, and anatase. Am Miner 2000;85:118-32. 